\title{
Happiness, Housework and Gender Inequality in Europe
}

\author{
Maria Sironi \\ University of Pennsylvania, Population Studies Center \\ Philadelphia, Pennsylvania (US) \\ msironi@pop.upenn.edu
}

Letizia Mencarini

(corresponding author)

Department of Statistics and Applied Mathematics at Political Science Faculty, University of Torino (I);

Collegio Carlo Alberto - Via Real Collegio, 30, 10024 Moncalieri (Torino, I)

Tel. +39 011.6705291, Fax +39 011.6705088

letizia.mencarini@unito.it

\section{Acknowledgements}

We are grateful for the comments from the anonymous reviewers and those from Arnstein Aassve, Bruno Arpino, Andrew Clark, Chiara Pronzato. 


\section{Introduction}

Does gender equality affect individual happiness? This is an interesting question, not least because over the last two decades, the Western world has experienced significant improvements in gender equality in almost all spheres of life. However, in many countries, roles concerning childcare and domestic work remain highly gender specific. In a few countries less so - an example being the Scandinavian countries, where time use data show that men are considerably more likely to participate in domestic chores than in other countries. The opposite is true in Southern European countries - as well as many continental countries. Do the gender systems have an important impact on individuals' psychological wellbeing? Certainly, gender inequality within the couple is an aspect that cannot be neglected when trying to explain reasons behind men and women's happiness. One might argue that improved gender equality has improved the general wellbeing of women, although its extent may depend on the context in which women live and operate. Gender division of labour within the family, clearly, varies considerably within and across countries. For instance, a woman living in a very traditional household - her being the one bearing the bulk of household activities, including childrearing, might report very different level of happiness if this household is located in Sweden, where generally gender inequality is less pronounced, compared to a country such as Greece, where strict gender roles prevail.

Our purpose here is to investigate the relationship between the unequal division of household labour between the partners and women's happiness ${ }^{\mathrm{i}}$. Using data from the second round of the European Social Survey (ESS), we provide detailed 
insights into this research question. Given the considerable differences among European countries in the level of reported happiness and female share of housework, we also consider directly to what extent the context matters for women's happiness. The ESS is ideal for this analysis and includes specific questions on subjective well-being, family organization and division of household labour in 26 countries. Given the relatively large number of countries involved in this survey, we are able to specify a multi-level regression model, which examines to what extent gender equality at the country level is able to explain variation in happiness at the individual level.

\section{Theoretical background: which relationship between happiness and housework?}

What is happiness? Are there differences by gender? How can the division of labour within the family, i.e. the amount of housework performed by female and male partner, be associated to heterogeneous levels of happiness?

Recent literature has investigated substantially on subjective well-being and several theories have been developed to define concepts like happiness (Veenhoven, 1993; Diener, 1984). Psychologists are not the only ones interested in well-being since it has been adopted by economists as one of the main elements to estimate and maximize the utility function. At the same time, considerable changes occurred in gender relations, whereby women devoted more time to education, gained power in the labor market and in public institutions. A large number of studies analyzed these changes and their possible consequences on individual and family life. Moreover, based on time use surveys, gender inequality 
has been taken into account also in terms of division of labor in the household among partners. If women achieved economic support and personal prestige outside the roles of wife and mother, the burden of housework and child care has remained mainly on their shoulders (Gershuny, 2000).

What has been rarely explored in the literature, however, is the relationship existing between subjective well-being and gender inequality, both at micro (in the household) and macro level (females' role outside the family). The main aim of this work is to investigate the interaction between these two dimensions, and how changes in gender roles towards parity in family domains, following those occurred in the public sphere, could enhance women's well-being.

There are several theoretical perspectives on happiness, firstly developed in the psychological field. The prominent theory is the so-called the "Set Point Theory", related to the concepts of adaptation and hedonic treadmill (Helson, 1964; Brickman and Campbell, 1971). According to this strand of research, individuals' judgments and reactions to current stimuli, whether they are negative or positive, depend on how their previous history has given them a reference point for comparison. The idea of a "hedonic treadmill" implies that, if people continue to adapt to their life course circumstances, improvements yield no real benefits and "worsened" conditions will not necessarily translate into a lower assessment of well-being. Every individual is presumed to have a predefined happiness level that he or she returns to as time goes by (Headey and Wearing, 1989; Larsen, 2000; Williams and Thompson, 1993). Given that subjective well-being is thought to be determined mainly by genetic endowments and personality traits, people who undergo changes for the worse or for the better will slowly adapt to these changes. Therefore major events have only temporary effects on happiness. The direct 
implication if this theory holds is that both individuals and policy makers cannot actually do very much to improve well-being of its citizens.

The set point theory gives a valid rationalization also to the so-called Easterlin paradox. In fact, according to economic theory and revealed preference, an increase in income should have a positive and lasting effect on happiness. Assuming that individuals maximize their utility over normal goods, then "more is definitely better". Conversely, as Easterlin (1995) and many psychologists and political scientists pointed out, growth of real income in Western countries over the last fifty years did not come with a corresponding rise in individuals' levels of happiness (Clark et al., 2007).

However, recent analyses focusing on the long run patterns of subjective wellbeing have made scientists revising also the "Set Point" hypothesis. That is, certain life events do indeed bring about long-lasting shifts of happiness. At macro level and looking at long term trends, studies in which comparisons can be made appear to show that satisfaction is higher and changes are more enduring in family related domains than in domains related to material standard of living, i.e. income (Veenhoven, 1993; Diener et al, 1999; Argyle, 2001). Headey (2006), using data from the German Socio-Economic Panel (SOEP), shows that the stability of life satisfaction diminishes slowly over time, meaning that long term changes in subjective well-being are plausible. Individuals who are most likely to record large changes in life satisfaction are those who score high on personality traits of extraversion or neuroticism, and also high on openness to new experiences. However, not only there is evidence of possible long term changes in subjective well-being, but also that the pace of adaptation to life events differs along with different experiences. Moreover, individuals tend to value losses more than gains and, if they are almost completely adaptable to pecuniary changes, this 
is not the case for non-pecuniary life circumstances. Widowhood, marriage and divorce, for instance, appear to produce permanent changes in individuals' set points (Frey and Sutzer, 2002; Zimmermann and Easterlin, 2006). The reason why level of adaptation differs with respect to life domains is found by considering different reactions of individuals' aspirations to changes in life events. When aspirations and actual circumstances change in tandem (as it often seems to be case for upward movements in income), one typically observes complete adaptation where individuals return to the original set point of happiness. If, however, aspirations change less than the actual change in circumstances, adaptation cannot be complete. An individual who is in a happy marriage, whose actual circumstances change positively, experiences a greater goal-fulfilment and, consequently, well-being increases (Easterlin, 2003).

According to the "prospect theory" (Kahneman and Tversky, 1979) and the "theory of planned behaviour" (Ajzen, 1991) even future expected changes in subjective well-being matter, determining decisions in the life-cycle, such as fertility decisions (Billari, 2009). It is what people think happiness is associated with that influences their decision making and individuals behave according to what they think makes them happy. Empirically this idea, predicting that happiness drives life course decisions, is not easy to test, although is important for instance, to consider that there might be some endogeneity and selection bias (i.e. are the happier people who marry more than others or simply marriage makes people happier?).

Of course perceptions and attitudes, affecting then intentions and then behavior, are linked to social norms and country settings. Social norms, embedding effects of past gender differences in family and working roles, are found to be internalised by both women and men, affecting individual happiness. For instance, 
there are double standards in appropriate earnings by gender, so that women earning less than men do not necessarily report differences in their job satisfaction and, consequently, in their subjective wellbeing (the so called paradox of “contented female workers"; Crosby, 1982; Lalive and Stutzer, 2010).

However the extent to which traditional norms are shared varies not only between countries, but also in time. Analyzing trends in the level of satisfaction in the last 35 years in the United States and 12 European countries, Stevenson and Wolfers (2009) documented a new puzzling paradox: women's declining subjective wellbeing, both absolutely and relatively, with respect to that of men. If in the 1970s, in all western countries, women reported higher subjective well-being than men, the declines in female happiness have eroded this gender gap until now when a new gender gap is emerging, with highly subjective well-being for men.

This shift has occurred through much of the industrialised world (Stevenson and Wolfers, 2009) and constitutes an apparent paradox because, by the most objective measures, women's lives have enormously improved over the past 35 years. The expanded women's opportunities in individual rights, health, education, job market, etc. should have increased their welfare. The rather puzzling paradox is that women's relative subjective well-being has fallen over a period in which most objective measures point to robust improvements in their opportunities. Stevenson and Wolfers (2009) suggest that this may be driven by a change in reference group or expectations for women. The increased opportunities available to women may have increased what women require declaring themselves happy, women's lives have become more complex and their wellbeing now likely reflects their satisfaction with more facets of life compared with previous generations. The happiness of women who are primarily homemakers 
reflects their satisfaction with their home life, whereas for working women reported happiness may reflect aggregate well-being over multiple domains.

This averaging over several domains may lead to lower average satisfaction because it is difficult to achieve the same degree of satisfaction in multiple domains. In addition, the increase in the female labor force participation may have led more women to compare their outcomes to those of the men around them. In turn, women might perceive their relative position lower than in the case with only women as a reference group. This change in the reference group may make women worse off or it may simply drive a change in their reporting behaviour. Furthermore their increasing expectations of gender equality were unmet especially within the family. Women's increased opportunities in the job market have led to an increase in the total amount of work they do, making them hedonically worse off (Krueger, 2007). This has also led to incoherence in the levels of gender equality in what McDonald (2000) calls the individual-oriented institutions of the public sphere and family-oriented institutions of the private sphere.Over the last decades, most Western countries have become characterized by a "stalled gender revolution". Whereas dramatic changes occurred in gender relations in general, whereby women entered in the public sphere and the labour market, the burden of housework and care has remained mainly on women's shoulders. Today women participate in the labour market more than ever before, and have reduced, at the same time, the amount of time devoted to unpaid work. Nevertheless, they have done so less than proportionally, thereby reducing their leisure time. Men have only slightly increased their involvement in family tasks, not acquiring a full share of family responsibility in childcare and housework (Blossfeld and Drobnic, 2001; Bernhardt, 2004; Neuwirth and Wernhart, 2008). Thus, gender relations within the family have changed very little. The observed 
increase in women's employment, not followed by men increasing their responsibility for domestic chores and care, characterizes the "stalled revolution" (Hochschild, 1990). The increase of women's work participation without a consequent redistribution of housework and childcare has often generated a real "dual-burden" for them, other than a "dual-presence".

In our work we investigate the core issues related to gender equality, providing a new perspective on the relationship between gender division of roles in a domestic sphere and the outcome in subjective wellbeing. We hypothesize that women who are engaged in a higher share of household work have a lower level of well-being with respect to those who work less at home.

In the literature there are few studies analyzing what happens if the partner does not contribute to the couple's health and his behaviour tends to generate marital conflict, and none referred directly to individual happiness. Research indicates that division of household labour between men and women are directly and indirectly linked to depression: performing larger amounts of routine and repetitive housework is associated with more frequent depression among women (Barnett and Shen, 1997; Glass and Fujimoto, 1994; Golding, 1990; Larson et al., 1994). The association is much weaker for men. Men's participation in the routine repetitive chores of cooking, cleaning and washing relieves women's burden, contributes to their sense of fairness, and hence lowers their chances of being depressed (Coltrane, 2000). It is possible that the way in which two co-residing partners share family and house care tasks influences women happiness through the following mechanism: not only doing more at home impacts negatively on the happiness, but also the amount of housework performed by the partner could affect the fairness perception and, consequently, life satisfaction. 
The actual division of housework within the household is a very direct measure of power and equality between men and women, at least for what concerns the role that they hold in a society. What cannot be disregarded, however, is how women perceive the division of household labour. In this respect, the context in which couples live is crucial. Previous research explicitly noted that contextual differences are not only present, but extremely important to understand household processes (Calasanti and Bailey, 1991; Kamo, 1994; Sanchez, 1993). The country of residence, for instance, matters for women's perception of fairness of the division of labour. The key reason is that gender inequalities are embedded in social institutions, which affect the roles individuals are expected to inhabit in those institutions. In turn, family labour allocations would be structured by gender differences in resources and power, and by differences in ideological valuations of labour (Curtis 1986; Katz, 1991, Davis, 2004). Hence, decisions concerning labour allocation are not just "rational" and efficient economic strategies, but also take into consideration cultural, moral, ideological and historical implications (Davis, 2004).

If the level of gender stratification in a country affects the expectations of individuals in their work and family lives, it affects also the individual perceptions of fairness of the division of household labour (Chaftez, 1990). In turn, we foresee that place of residence and context play an important role in the relationship between the women's share of household work and their happiness. If they live in a country where doing almost all the tasks within the household is perceived as "normal" and fair, it could be that housework has not a large impact on their happiness. Conversely, for a woman with a huge housework load in a more "egalitarian" country, the negative effect on happiness would be stronger. 
Summing up, levels of happiness among women turn out to be very different across Europe and this can be associated to the interactions between partners within the household. Women in countries where the level of gender stratification is lower have more bargaining power within marriages (or cohabitations) and are able to obtain a more equal sharing of household work. This explanation, however, may be only partial and we need to consider gender inequality not only inside the family but also in a more general sense. Women's overall empowerment and conditions in a country, captured, for example, by female labour force participation rates, educational attainments and political achievements, have possibly a strong impact on their individual well-being.

\section{Data}

Our analysis is based on the European Social Survey (ESS). These surveys have been mapping attitudinal and behavioral changes in Europe's social, political and moral climate since 2001. So far four rounds have been conducted and completed: 22 countries were included in Round 1 (2002), 26 in Round 2 (2004), 25 in Round 3 (2006), and 21 in Round 4 (2008). Every round contains a so-called core module, which remains unchanged over survey rounds and has been designed to chart and explain the interaction between Europe's changing institutions and attitudes, beliefs and behavioral patterns of its diverse populations. The first part of the survey pertains to individuals' values and ideological orientations. These may be the cause of people's opinions, behaviours and actions, thus becoming an important driver behind the social, political and economic change within their respective societies. Secondly, the ESS considers individuals' cultural and 
national orientations, a feature being of key importance given the process of unification of the Western European countries. The third main area concerns the underlying social structure of society. Since values and social change are strongly driven by the social composition (e.g. education and occupations), identification of these factors is essential in drawing a correct picture of the social climate. The questionnaire includes also a second part that varies over time (the so-called Rotating Module).

For our analysis, we use the second round (2004), given that it includes variables necessary for measuring the outcomes of interest. In particular, the questionnaire asks specific questions on family, work, and well-being, which contain information on the combination of family life, housework and happiness. In order to assess the dynamics taking place inside the household between women and their partners, we restricted our focus on women between 20 and 50 years of age, who co-reside with a partner (8,031 observations out of the original 47,537 sample).

\section{Variables and descriptive findings}

\subsection{Measuring happiness}

Traditionally and strongly influenced by economics, household and individual well-being is measured by income or other monetary measures such as consumption expenditure. One drawback of this approach is that an assumption has to be imposed on how individuals within a household share the income, the second is that well-being derives from many other sources than income and consumption. As a result, recent research has started looking into alternative 
measures of well-being where the level of happiness has become popular. Individuals are asked directly about their happiness, which then presumably would be the sum of benefits derived from income and consumption, but also other non-monetary factors that cannot in any case be measured very easily.

The key question is of course whether happiness indeed measures individuals' well-being in a satisfactory way. It is positively correlated with income and wealth, as well as other life events which we normally would consider as positive (i.e. marriage) and negatively with life events of a less happy nature (i.e. death or divorce). Consequently, happiness is likely, at least on average to give a good indication of well-being. On the other hand, the current level of happiness when asked in a survey may depend on a range of factors that we ideally would like to disregard in our analysis. It could be for instance, that an individual had a cold or was feeling ill the day of interview, and therefore reported a lower level of happiness than would otherwise be the case. Still, in so far such noise in the data is random, it should not affect the overall conclusions of the analysis.

Typically a question about happiness is posed as follows: "Taking all things together, how happy are you with your life?", or "How satisfied are you with your life?", and generally the answer is given on an ordinal scale, ranging from 0 (extremely unhappy) to 10 (extremely happy). But does a question asking about current happiness on some ordinal scale really provide a good assessment of current circumstances related to different life domains (family life, employment, economic wealth, etc.)? Moreover, it is difficult to understand how people answer to this kind of questions. Do they answer by considering themselves with respect to their own situation in the past, to the other individuals around them or do they try to give a comprehensive judgment, all things considered? Hence, it is hard to 
say if it is possible to carry out inter-temporal or interpersonal comparison in happiness scores. However, despite measurement issues, and in particular the reliability and validity of the replies, happiness is now widely used. The conclusion from existing studies is that these subjective indicators, far from being without problems, do reflect individuals' feelings of psychological well-being and happiness (Diener, 1984; Veenhoven, 1993).

In our analysis the dependent variable is measured by the question "Taking all things together, how happy would you say you are?". The answer is given on an ordinal scale, ranging from 0 (extremely unhappy) to 10 (extremely happy). Respondents tend to answer positively and more than half of the sample reports values of 7 or higher, producing a skewed distribution of happiness. Even though the distribution of happiness is concentrated toward high values, it seems that there are systematic differences in the assessment of subjective well-being among the 26 countries included in the analysis. This can be easily seen in Table 1 that reports descriptive statistics on the variables just mentioned above. Although levels of average happiness are fairly high, we notice that the associated standard deviation is not negligible (and over 2 for six countries). Ranking among countries shows Iceland and Northern countries in leading positions and Italy and Ukraine in the last ones. The reason why reported happiness is generally so high in the sample could be related to selection issues, as we are considering women who are co-residing and they may be more satisfied with their life relative to single women ${ }^{\mathrm{ii}}$.

\section{Table 1 here}




\subsection{Measuring housework}

Housework, and childcare, characterizes the family role-set. The division of tasks within the family between men and women is everywhere influenced by each member of the couple being involved in paid work. However, worldwide, there is a persistent female specialization in household tasks. Only in the Scandinavian countries there is now a consolidated habit amongst men to undertake domestic and family activities on an equal basis (Gershuny 1995, 2000).

In the ESS data, the amount of household work is defined as things done around the home, including cooking, washing, cleaning, care of clothes, shopping, maintenance of property, but not including childcare and leisure activities (Mills et al, 2008). Individuals are asked both the total time people in home spend on housework on a typical weekday and weekend, and the part of total time they are engaged in. This share ranges from 1 , meaning "none or almost none", to 6 , meaning "all or nearly all of the time". After considering the distribution of women's share of housework, we employ in the model a dummy variable which is equal to 1 when the female respondent is engaged in a large share of household labour (more than $75 \%$, i.e. when the original ordinal variable on the share of housework is equal to or greater than 5) and 0 otherwise. A preliminary analysis of this variable shows that the differences in time and share between a typical weekday and the weekend are extremely small. For this reason we take into account only the ones referring to the typical weekday.

As we can see from the figure below (see Figure 1), there is high heterogeneity in the portion of household tasks carried out by European women. The country where apparently women work relatively more inside the household is Greece, with $81 \%$ of women in the sample doing more than $75 \%$ of household 
work. The general picture is not different in Turkey and Portugal, which report a percentage around $76 \%$. The first of the 9 countries where less than half of the respondents is engaged in less than $75 \%$ of housework is Poland. In this group we find only Eastern European countries (Poland, Estonia, Slovenia and Ukraine) and Scandinavian ones (Iceland, Finland, Norway, Sweden and Denmark). In other former socialist countries the percentages of those who engage in a large share of housework are slightly higher, like Hungary (56.25\%), Czech Republic (51.89\%) and Slovakia (50.6\%). The large diversity can be detected not only in the high variability of percentages, but also in the fact that countries located in the same area and with the same kind of welfare regime and institutions report very different values, e.g. Luxemburg and Belgium. The results from ESS data are consistent with those, more appropriate, obtained by Time use budget surveys (Anxo et al., 2010; Gershuny, 2000; OECD, 2007).

\section{Figure 1 here}

\subsection{Happiness and share of housework at country level}

To have a more accurate picture on the association of women's share of housework with happiness, it is interesting to investigate the relationship between the average level of subjective psychological well-being in each country and the respective percentage of respondents engaged in more than $75 \%$ of total housework. An overview of this relationship is provided in Figure 2. It reveals that the link between the two variables is not linear and that every country has its own combination (Pearson correlation coefficient $=-0.1861 * * *)$. However, a more detailed analysis of the figure shows some kind of clustering among countries, in particular according to the institutional context and the geographic 
location. Northern countries, for instance, all present a high average happiness and relatively few respondents working a lot in the household. The opposite situation occurs in Southern Europe, like in Greece, Portugal and Turkey, whereas the percentage of women engaged in a large share of household labour is a bit lower in Italy. Spain is the outlier of this group, and seems to match more with countries of continental Europe, such as the Netherlands, France and Luxemburg. Here the average happiness ranges between 7.5 and 8.5, and the portion of "hard core house workers" is around $60 \%$. Finally, in Eastern Europe we observe values of both variables a bit lower with respect to continental countries. Therefore, the nation of residence and context appears to play an important role in the considered relationship. Hence, taking into account the underlying differences among countries, it might happen that a clearer connection comes out; this is exactly what a model with a multilevel structure allows to investigate and what we look at in the next section.

Figure 2 here

\section{Determinants of female happiness: which role for housework?}

\subsection{Multilevel estimation}

In order to examine the possible determinants of happiness and, in particular, the impact of women's share of housework, we implement a series of ordered probit regressions with a multilevel structure. Data collected in the ESS present a clustered structure: Information is gathered at individual level and individuals are grouped within countries. We introduce a two-level model, which allows for 
grouping of individual outcomes within countries. This means that the variation in the outcome, i.e. happiness, is decomposed into a between-country component and a within-country one. A null model without any explanatory variable simply tells us how much of the variance in happiness is due to individual level variation and country level variation. Statistically, failing to recognize this hierarchical structure leads to underestimation of the standard errors, producing statistical significance when coefficients are in fact not significant (Goldstein, 2003). A more substantive benefit of the multi-level model is that we can include country level variables and therefore assess the importance of country characteristics in explaining individual level variation in happiness. This is important, not only because the descriptive statistics show substantial country differences, but also because such differences are also reported in the existing literature (Calasanti and Bailey, 1991; Kamo, 1994; Sanchez, 1993). The argument is that country of residence influences women's perception of fairness of the division of labour. The level of gender inequality in social institutions, for example, shapes people expectations about the role they need to take in the society. Consequently, our analysis cannot ignore the fact that women under consideration live in 26 dissimilar countries.

Our model can be written as follows:

$$
\text { Happiness }_{i j}=\alpha_{0}+\beta H S_{i j}+\mu X_{i j}+\gamma G I_{j}+u_{0 j}+\varepsilon_{i j}
$$

where Happiness $_{i j}$ is the level happiness - ranging from 0 (extremely unhappy) to 10 (extremely happy) - of individual $i$ in country $j ; H S_{i j}$ is the dummy variable that is equal to 1 if a woman is engaged in a share of household labour greater than $75 \% ; X_{i j}$ is a vector of women's demographic and socio economic characteristics; while $G I_{j}$ represents the level of gender inequality at country 
level. $u_{0 j}$ is the country specific error term and $\varepsilon_{i j}$ is the individual specific error term.

Female characteristics' vector includes variables such as the number of working hours outside the household, the level of income and ability to obtain unpaid assistance for housework. Women's position in the job market and the amount of time they devote to it is very influential in the relationship between housework and happiness. First, the time available for home activities - including housework - is reduced. Secondly, working outside the home has a positive income effect, which for instance could enhance possibilities for hiring a housekeeper. Third, obviously there are many factors influencing this relationship, such as income, age, health, religion and employment. We expect this negative impact to be stronger for women who are employed part-time or full-time, given that they are often trapped into a double burden of both market work and domestic duties in the household (Ericson, 2008).

Compared to housewives, working women tend to report greater happiness, whether they work part-time or full-time. This happens because job satisfaction is one of the three most important predictors of overall happiness, the other two being marriage and family satisfaction (Argyle, 2001; Clark, 1997). Hence, from the number of working hours per week (overtime excluded) according to the worker's contract, we create three different binary variables referring to three different categories: women working up to 10 hours per week, those working between 11 and 30 hours and those working more than 31 hours per week. Only in Turkey the percentage of those working more than 10 hours per week is only 10\%. Also in Southern European countries (Greece, Italy, Spain and Switzerland) this share is quite low. In all the remaining countries more than half of the sample works at least 10 hours per week. The only country in which "part-time" working 
scheme (10-30 hours per week) is more common than the "full-time" one is Netherlands, where women working "part-time" are $40 \%$ while those working "full-time" are just $25 \%$ of the sample.

Financial resources are another factor to be considered when looking at individual happiness. Existing evidence shows that income raises happiness (Clark et al, 2007; Frey and Stutzer, 2002; Blanchflower and Oswald, 2004), especially in the lower part of the income distribution (Argyle, 2001), but the effect is not always very strong and long lasting (Easterlin, 2001). The ESS records income by using a variable, which reflects twelve income brackets ranging from less than $€ 1800$ to $€ 120000$ or more and refers to household income. Respondents are asked to place their household income in the respective intervals. Based on this classification, we estimate the median income for each country. There is obviously substantial heterogeneity of income levels and purchasing power across countries. However, by using the midpoint of the income distribution from each country, we are able to construct a relative income variable. We include a binary variable in the analysis, taking value 1 if household income is above or equal to the median income in that country. The extent to which income is positively associated with happiness may depend on the household size. A high income may not be strongly associated with happiness if the number of household members is also large $\mathrm{i}^{\mathrm{iii}}$.

Another issue particularly important for our analysis is the extent to which the respondents are able to obtain assistance for housework from individuals external to the family. This kind of help is either paid, in the case a housekeeper is hired, or unpaid, when for instance grandparents take care of their grandchildren. The second round of the ESS provides information only about unpaid help and this variable is equal to 1 if the respondent can count on someone for help with housework and 0 if not. The number of respondents reporting that they received 
unpaid help from outside is surprisingly high for every country analyzed (see Table 1). Moreover, the two countries where less than 60 percent (i.e. being at the lower end of the distribution) of respondents can count on outside help, are Greece and Turkey. The highest percentages are found for Northern countries, Denmark, Iceland and Sweden, being the highest where more than $90 \%$ of interviewed women get unpaid help. This kind of help usually comes from parents of respondents or from their children, when they grow up.

Finally, in the analysis we consider also the age of respondents, self reported health, the frequency of church attendance (the variable is equal to 1 if the respondent attends religious services at least once a month, 0 otherwise) and the number of children in the household. This last variable is of particular interest, given that children have mixed effects on subjective well-being and exert their influence via two different mechanisms. Firstly, they increase happiness about family life. Secondly, the added financial burden of children reduces satisfaction with one's economic situation (Zimmermann and Easterlin, 2006). The fact that respondents live with a partner induces the percentage of those with at least one child in the household to be high.

The most relevant country level factor for our analysis is the intensity of gender inequality. To grasp women's overall empowerment and conditions in a country, we exploit two macro variables. The first is the female labour force participation rate and an index, the Global Gender Gap, which considers several different life domains. The Female Labour force participation rate refers to 2004, given that our respondents were interviewed exactly in that year (see Table 2). We notice that in all countries of Northern Europe the rate of women between 15 and 64 years of age, who are working (or who are unemployed but looking for a job), is greater than $70 \%$. The country with the highest rate is Iceland, followed by Norway and 
Sweden. On the contrary, very low values are recorded in Turkey (29\%) and Italy (49.5\%), and more generally in Eastern and Southern Europe. Countries where a large percentage of women is part of the labour market are usually the same countries where average happiness is high.

The Global Gender Gap is a more general indicator of gender inequality existing in a country. A Global Gender Gap Report series was launched in 2006 by the World Economic Forum, aimed at capturing the magnitude of the gap between women and men in four critical areas: economic participation and opportunity, political empowerment, educational attainment and health and survival It ranks countries according to gender equality rather than women's empowerment (Global Gender Gap Report 2006). The first year available is 2006 and we use that year, assuming that the general picture in 2006 is not very different to the one in 2004, relevant for our analysis. It ranges from 0.59 (Turkey) to 0.81 (Sweden), with the maximum possible value being 1 (equality between men and women). Together with Sweden, also Norway, Finland and Iceland are in a top position, immediately followed by Germany, United Kingdom, Ireland and Spain. The lowest ranking, instead, belongs to Turkey, Italy and Greece and the index is quite low in Eastern Europe.

\section{Table 2 here}

In the multi-level setting we are of course interested in the effect and the significance of such variables. But we are also interested in understanding how much country characteristics can explain the country variation in the outcome.

As a general estimation strategy, a null model is first estimated, only including the constant. Next, through different extensions, both individual level 
variables and country level ones are incorporated in the model. In order to obtain the fraction of residual variability that can be attributed to country level effects it is useful to define the "intra-class" correlation coefficient, namely the ratio between country variance and the total variance:

$$
\rho=\frac{\operatorname{Var}\left(u_{0 j}\right)}{\operatorname{Var}\left(u_{0 j}\right)+\operatorname{Var}\left(\varepsilon_{i j}\right)} ;
$$

where $\varepsilon_{i j}$ and $u_{0 j}$ are assumed to be independent and normally distributed. Through the intra-class correlation coefficient $\rho$ we can find out which is the proportion of total variance accounted for by between-country variation. When country-level variables are included in the model throughout the extensions, we expect the intra-class correlation coefficient to decrease (assuming the county level variables have explanatory power).

\subsection{Results and discussion}

Estimates of the ordered probit multilevel regressions are reported in Table 3 and Table 4. We perform the analysis both on the whole sample of 8,031 women between 20 and 50 and on a sub-sample of 4,968 working (more than 10 hours per week) women. The reason why we want to focus our attention separately on working women is that, in this case, we expect hours of work to interact with happiness in two different but opposite ways. On one hand, working women usually report a greater happiness, whether they work part-time or full-time, with respect to housewives (Clark, 1997). On the other hand, the effect of being employed indirectly decreases happiness, by forcing them into a double burden of both market work and domestic duties in the household, if the share of housework 
is fairly high. Hence, by looking at them separately we are able to understand which one of the two effects is stronger.

The general hypothesis we formulated is that women who are engaged in a higher share of household work have a lower happiness with respect to those who work less at home. This expectation is confirmed in model (2), where we observe a negative and strongly significant coefficient for the share of housework greater than $75 \%$, independently on the total number of household labour hours ${ }^{\mathrm{iv}}$. One of the most interesting results concerns contracted hours in paid work. In model (2) we observe that there is no apparent difference between housewives and women working up to 30 hours per week. However, a small change occurs when the weekly working hours are more than 30 . Women belonging to this category are slightly less happy then the rest of the sample. Hence, there is an indication that the negative effects of the dual burden trap overcome those of increased happiness through job satisfaction. The intra-class correlation coefficient related to this model is 0.12 , meaning that $12 \%$ of the total variance is due to cross-country variability. Since $\rho$ is not much higher than that of the null model (0.111), it seems clear that happiness differences among countries cannot be explained by through individual level differences.

As previously discusses, if they live in a country where doing almost all the tasks within the household is perceived as "normal" and fair, it could be that housework has not a large impact on their happiness; conversely, a woman with a huge housework load in a more "egalitarian" country should feel even more depressed. As a matter of fact, when we test in model (3) the impact that having a share of housework greater than the country median has on happiness, we notice that the coefficient is negative and significant at the $5 \%$ level. This effect is less strong than the one reported in model (2), but still very much present. 
In models (4) and (5) we start introducing country-level variables as a means to better understand the effect of the intensity of gender inequality in a given country. First we look at the female labour force participation rate and we observe that nothing changes with respect to model (2). That is, individual level variation is stable when including the macro variable. Moreover, the effect of female labour force participation is small, but positive and significant. More interestingly, the variance component representing variation between countries has diminished markedly, from 0.136 to 0.096 , meaning that this indicator is able to explain $29.4 \%$ of the between-country variation. Participation of women to the labour market is then a characteristic which distinguishes countries and may explain part of the international differences in women's happiness. Investigating the impact of gender inequality between men and women, considering not only the occupational field, but also the gender gap in education and political power the results are not much different. In model (5) the share of household work coefficient maintains its explanatory power and the between-country component of the variance decreases to 0.08 . In this case, accounting for the global gender gap explains $41.2 \%$ of the variance across countries. The intra-class correlation coefficient comes down to 0.074 , suggesting that only $7.4 \%$ of the total variance is due to cross-country variability (after controlling for gender inequality). Hence, our expectations about the fundamental role of women's overall empowerment and of gender inequality in shaping women psychological well-being find corroboration in our data. When we focus our attention on working women only, the picture is reinforced.

As reported in Table 4, models (7), (9) and (10) illustrate that a large share of housework affects women happiness negatively, and the effect is much stronger compared to the case when the whole sample is used. This result confirms that the 
dual burden trap exists and exerts its influence. An interesting aspect of our results in Table 4 is that, in all the considered models, the covariate measuring the number of children living in the household is never significant. It seems that, among working women, having children in household does not affect their happiness. This is in contrast to the case when housewives were included in the sample. Then the coefficient was always significant and positive even if rather small. It might be the case that those working outside the household have much less spare time and, consequently do not miss the presence of children (if they had some, who now live by themselves) or do not feel the need to experience motherhood. As we already observed in Table 3, working full-time, more than 30 hours per week, has a negative impact on happiness, and we can argue that for this group of female respondents the dual burden is heavier than for part-time workers, resulting in a lower assessment of psychological well-being.

As far as the variance decomposition is concerned, the null model (6) reports an intra-class correlation coefficient of 0.136 , a bit higher than that of model (1). Also in this case the introduction of individual covariates in the analysis has a negligible impact on the variance across countries. However, when we include the female labour force participation rate, it explains $35.3 \%$ of the between-country variability and brings down $\rho$ to 0.088 . Also the Global Gender Gap has a strong explanatory power for the country differences, as it accounts for $42 \%$ of the variance across countries. In model (10), after controlling for gender inequality, between-country component is only $8 \%$ of the total variance. This suggests that country-level variables, denoting gender inequality, are able to explain international differences in women's happiness, hence the effect being stronger the sample consist of working women only. 
We include in the regression other individual variables and their coefficients do not change dramatically in the following specifications. As expected, happiness decreases with age and being healthy has a strong positive impact on this psychological well-being. Confirming a rich literature about the effects of religion on personal well-being, we find that frequent church attendance also outside special holy days is positively associated with happiness. It has been argued that one of the possible reason why religion makes a difference to people's lives is that it provides social networks, favourably affects physical and mental health, school attendance and reduces deviant activity (Lehrer, 2004; Snoep, 2008). Moreover, it seems to be true also controlling for demographic variables such as age, income and marital status (Luttmer, 2005). As predicted, receiving unpaid help with housework by someone external to the household and having a fairly high income are positively associated to happiness. Concerning this last point, it is important to specify that controlling for the number of household members does not change magnitude and significance of income coefficient. Apparently, mothers with children still living in the household are happier than mothers with old sons/daughters or women without children, as the relative coefficient comes out to be positive and significant.

Table 3-4 here

\section{Conclusion}

Investigating the relatively unexplored relationship between gender inequality inside the couple and women's happiness across European countries, we found 
empirical evidence to our hypothesis that a large share of housework negatively affects women's happiness, in particular for those employed for more than 30 hours per week, with respect to being employed part-time or being a housewife. Undeniably, the dual-presence is therefore a full-blown "dual-burden".

A second important result is that women's unhappiness concerning unequal division of labour cannot be judged only in "absolute" terms, but also in "relative" terms. We found that being engaged in housework that exceeds the median amount recorded in a specific country affects respondents' happiness in a negative way: a woman, living in a country where partners usually share equally household chores, feels more unhappy if she has to perform the bulk of total housework; conversely, where (e.g. Greece) women are, on average, in charge of almost all housekeeping, sharing part of it with the partner decreases the negative effect of housework on respondent's happiness.

The third result comes from investigating the possible determinants of the variation in happiness in Europe and looking at gender inequality from a wider perspective. That is, looking at the importance of gender discrimination at country level in shaping women's well-being. More than $40 \%$ of the variance across countries can be explained by gender inequality between men and women, considering not only the job market, but also the gender gap in education and political power.

Unfortunately, the European Social Survey is a cross-sectional dataset. Therefore we cannot say whether the negative effect of a large share of housework and of gender gap on women's happiness is lasting over time or not. However, we can argue that caring about gender inequality both inside and outside the household is fundamental to understand the dynamics behind women's assessment of happiness in the countries of the European region. 
In conclusion, our results prompt the idea that subjective well-being should play a more central role in research and policy concerning family. These results are even more evident when we recall that, on one hand, gender equality within the family has been proved to be linked at macro (McDonald, 2000) and micro level (i.e. Mills et al., 2008) to higher fertility intentions and behaviour. On the other hand, the "happiness commonality" theory (Billari, 2009) sustains a positive link between subjective well-being and fertility, again both at micro and macro level. The main idea behind this theory is that the quest for happiness, and the compatibility between happiness and childbearing, is the "commonality" that may shed some light on why fertility levels are so heterogeneous across developed countries.

We believe the association between gender equality within the couple and happiness to be the missing link between the two theories and an important intermediate variable to be considered when analysing diverging family and fertility contexts of Southern and Northern European countries. 


\section{References}

Ajzen I. (1991), The theory of planned behavior, Organizational Behavior and Human Decision Processes, 50, 179-211.

Anxo D., Flood L., Mencarini L., Pailhé A., Solaz A., Tanturri M.L. (2010), Gender differences in time-use over the life-course. Acomparative analysis of France, Italy, Sweden and the United States, Feminist Economics, forthcoming.

Argyle M. (2001), The Psychology of Happiness, New York: Routledge.

Barnett R. C., Shen Y. (1997), Gender, high- and low-schedule-control housework tasks, and psychological distress: A study of dual-earner couples, Journal of Family Issues, 18, 403-428.

Bernhardt E.M. (2004), Is the Second Demographic Transition a useful concept for demography? Vienna Yearbook of Population Research 2004: 25-28.

Billari F. C. (2009), The Happiness Commonality: fertility decisions in lowfertility settings, keynote papers of panel discussions at UNECE Conference "How Generations and Gender Shape Demographic Change", Geneva 14-16 May 2008.

Blanchflower D., Oswald A. (2004), Money, Sex and Happiness: An Empirical Study, Scandinavian Journal of Economics, Blackwell Publishing, vol. 106(3), pages 393-415, October.

Blossfeld, H.P. and Drobnic, S. (2001). A cross-national comparative approach to couples' Career. In: Blossfeld, H.P., Drobnic, S. (eds.). Careers of couples in contemporary society. New York: Oxford University Press: 3-15.

Brickman P., Campbell D.T. (1971), Hedonic relativism and planning the good society. In: Apley, M.H. (Ed.), Adaptation-Level Theory: A Symposium. Academic Press, New York, pp. 287-302.

Calasanti T., Bailey C. (1991), Gender Inequality and the Division of Household Labor in the United States and Sweden: A Socialist-Feminist Approach, Social Problems, 38, 34-53.

Chaftez J. (1990), Gender Equity: An Integrated Theory of stability and Change, Newbury Park, CA: Sage Publishers.

Clark A. (1997), Job satisfaction and gender: why are women so happy at work?, Labour Economics, 4, 341-372.

Clark A., Frijters P., Shields M. (2007), Relative Income, Happiness and Utility: An Explanation for the Easterlin Paradox and Other Puzzles, IZA Discussion Papers 2840, Institute for the Study of Labor (IZA).

Coltrane S. (2000), Research on Household Labor: Modeling and Measuring the Social Embeddedness of Routine Family Work, Journal of Marriage and Family, 62O(4), 1208-1233.

Crosby F. (1982), Relative deprivation and working women. New York: Oxford University Press.

Curtis R. (1986), Household and Family in Theory on Inequality, American Sociological Review, 51, 168-183. 
Davis S. (2004), Is Justice Contextual? A Cross-National Analysis of Women's Perceptions of Fairness of the Division of Household Labor, Carolina Population Center - Unpublished manuscript.

Diener E. (1984), Subjective well-being, Psychological Bulletin, volume 95(3): pp. 542-75.

Diener E., Suh E.M., Lucas R.E., Smith H.L. (1999), Subjective well-being: Three decades of progress, Psychological Bulletin, 25, 276-302.

Easterlin R. (1995), Will raising the incomes of all increase the happiness of all?, Journal of Economic Behavior and Organization, vol. 27, pp. 35-47.

Easterlin R. (2001), Income and Happiness: Towards a unified Theory, Economic Journal, volume 111(473): pp. 456-484.

Easterlin R. (2003), Explaining Happiness, Proceedings of the National Academy of Sciences, 100:19, 11176-11183.

Ericson T. (2008), Equalization of paid working hours in the dual-earner household: Does it increase women's double burden?, Working Papers in Economics 291, Göteborg University, Department of Economics.

Frey B., Stutzer A. (2002), What Can Economists Learn from Happiness Research?, Journal of Economic Literature, American Economic Association, vol. 40(2), pages 402-435, June.

Frey B., Stutzer A. (2002), The Economics of Happiness, World Economics, NTC Economic \& Financial Publishing, PO Box 69, Henley-on-Thames, Oxfordshire, United Kingdom, RG9 1GB, vol. 3(1), pages 25-41, January.

Frijters P., Beatton T. (2008), The mystery of the U-shaped relationship between happiness and age, NCER Working Paper Series 26, National Centre for Econometric Research.

Gershuny J. (1995), Change in the division of domestic work: micro-sociological evidence, DIW Discussion Paper 107.

Gershuny J. (2000), Changing times: work and leisure in post-industrial society, Oxford, Oxford University Press.

Glass J., Fujimoto T. (1994), Housework, paid work, and depression among husband and wives, Journal of Health and Social Behavior, 35, 179-191.

Goldstein H. (2003), Multilevel Statistical Models, Oxford University Press.

Golding J. M. (1990), Division of household labor, strain, and depressive symptoms among Mexican Americans and Non-Hispanic Whites, Psychology of Women Quarterly, 14, 103-117.

Headey B. (2006), Happiness: Revising Set Point Theory and Dynamic Equilibrium Theory to Account for Long Term Change, Discussion Papers of DIW Berlin 607, DIW Berlin, German Institute for Economic Research.

Headey B., Wearing A. (1989), Personality, life events, and subjective well-being: Toward a dynamic equilibrium model, Journal of Personality and Social Psychology, 57, 731-739.

Helson H. (1964), Adaptation-Level Theory. New York: Harper.

Hochschild A. (1990), The Second Shift, New York, NY: Avon Books. 
Kamo Y. (1994), Division of Household Work in the United States and Japan, Journal of Family Issues, 15, 348-378.

Kahneman D., Tversky A. (1979), Prospect Theory: An Analysis of Decision under Risk, Econometrica, Vol. 47, No. 2, pp. 263-292.

Katz E. (1991), Breaking the Myth of Harmony: Theoretical and Methodological Guidelines to the Study of Rural Third World Households, Review of Radical Political Economics, 23, 37-56.

Krueger A. (2007), Are We Having More Fun Yet? Categorizing and Evaluating Changes in Time Allocation. Brookings Papers on Economic Activity, 2, 193-215.

Lalive R., Stutzer A. (2010), Approval of equal rights and gender differences in well-being, Journal of Population Economics, Volume 23, Number 3, pp. 933-962

Larsen R. J. (2000), Toward a science of mood regulation, Psychological Inquiry, $11,129-141$.

Larson R., Richards M., Perry-Jenkins M. (1994), Divergent worlds: The daily emotional experience of mothers and fathers in the domestic and public spheres, Journal of Personality and Social Psychology, 67, 1034-1046.

Lehrer E. (2004), Religion as a determinant of economic and demographic behaviour in the United States, Population and Development Review, 30, 707-726.

Luttmer E. (2005), Neighbours as negatives: Relative earnings and well-being, Quarterly Journal of Economics, 120, 963-1002.

McDonald, P. (2000). Gender equity in theories of fertility transition. Population and Development Review 26(3): 427-439.

Mills M., Mencarini M., Tanturri M. L., Begall K. (2008), Gender equity and fertility intentions in Italy and the Netherlands, Demographic Research, Max Planck Institute for Demographic Research, Rostock, Germany, vol. 18(1), pages 1-26, February.

Neuwirth, N. and Wernhart, G. (2008). Work-life balance reconsidered. Time allocation within partnerships: Germany, UK and Austria. Vienna: Austrian Institute for Family Studies, University of Vienna (OIFS working paper 67).

OECD (2007) Babies and Bosses. Reconciling work and Family Life, A synthesis of findings for Oecd Countries, Paris, Oecd Publications.

Sanchez L. (1993), Women's Power and the Gendered Division of Domestic Labor in the Third World, Gender and Society, 7, 434-459.

Snoep L. (2008), Religiousness and happiness in three nations: a research note, Journal of Happiness Studies, 9, 207-211

Stevenson B., Wolfers J (2009), "The Paradox of Declining Female Happiness", American Economic Journal: Economic Policy, 1(2): 190-225.

Veenhoven R. (1993), Happiness in Nations, Subjective Appreciation of Life in 56 Nations 1946-1992, Rotterdam: Erasmus University 
Williams D. E., Thompson J. K. (1993), Biology and Behavior: A set-point hypothesis of psychological functioning, Behavior Modification, 17, 4357.

Zimmermann A., Easterlin R. (2006), Happily Ever After? Cohabitation, Marriage, Divorce, and Happiness in Germany, Population and Development Review, The Population Council, Inc., vol. 32(3), pages 511528. 
TABLE 1: Descriptive Statistics of variables used in the analysis, by Country (Source: own elaboration on 2004 ESS data)

\begin{tabular}{|c|c|c|c|c|c|c|c|c|c|c|c|}
\hline Country & Num Obs & & $\begin{array}{l}\text { erage } \\
\text { piness }\end{array}$ & $\begin{array}{c}\text { Share of } \\
\text { housework } \\
>75 \%\end{array}$ & $\begin{array}{c}\text { Bad } \\
\text { Subjective } \\
\text { Health }\end{array}$ & $\begin{array}{c}\text { Church } \\
\text { Attendance } \\
\text { (once a month } \\
\text { or more) }\end{array}$ & $\begin{array}{l}\text { At least } \\
1 \text { child }\end{array}$ & $\begin{array}{l}\text { With unpaid } \\
\text { help }\end{array}$ & $\begin{array}{c}\text { High } \\
\text { Income } \\
(\geq \text { country } \\
\text { median })\end{array}$ & $\begin{array}{l}\text { 10-30 } \\
\text { Working } \\
\text { Hours } \\
\text { per week }\end{array}$ & $\begin{array}{c}>30 \\
\text { Working } \\
\text { Hours } \\
\text { per week }\end{array}$ \\
\hline Code & $\#$ & Value & St. Dev. & $\%$ & $\%$ & $\%$ & $\%$ & $\%$ & $\%$ & $\%$ & $\%$ \\
\hline AT & 107 & 7.93 & 1.87 & 52.3 & 2.8 & 32.7 & 71.9 & 81.3 & 67.2 & 28.0 & 32.7 \\
\hline $\mathrm{BE}$ & 304 & 7.93 & 1.39 & 53.9 & 4.2 & 11.8 & 75.9 & 75.6 & 57.5 & 27.3 & 43.4 \\
\hline $\mathrm{CH}$ & 370 & 8.28 & 1.33 & 65.6 & 1.6 & 25.4 & 67.3 & 82.7 & 83.7 & 25.6 & 31.8 \\
\hline $\mathrm{CZ}$ & 397 & 7.28 & 1.95 & 51.8 & 4.5 & 9.8 & 76.8 & 86.4 & 59.4 & 5.7 & 59.1 \\
\hline $\mathrm{DE}$ & 491 & 7.48 & 1.87 & 59.6 & 6.1 & 19.7 & 73.5 & 78.6 & 60.9 & 26.8 & 34.2 \\
\hline DK & 275 & 8.42 & 1.31 & 30.5 & 2.1 & 9.4 & 70.9 & 96.3 & 76.0 & 13.8 & 65.0 \\
\hline $\mathrm{EE}$ & 320 & 7.23 & 1.65 & 44.6 & 3.1 & 6.5 & 79.6 & 82.1 & 89.3 & 6.2 & 70.3 \\
\hline $\mathrm{ES}$ & 275 & 7.65 & 1.67 & 64.7 & 4.0 & 28.3 & 78.9 & 70.5 & 52.7 & 10.5 & 48.3 \\
\hline FI & 343 & 8.39 & 1.18 & 42.2 & 2.3 & 9.9 & 68.2 & 86.0 & 81.6 & 6.4 & 67.6 \\
\hline FR & 334 & 7.81 & 1.66 & 59.8 & 4.1 & 10.4 & 78.1 & 76.6 & 70.3 & 21.5 & 54.1 \\
\hline GR & 454 & 7.38 & 1.79 & 80.8 & 1.3 & 55.5 & 80.6 & 54.1 & 65.2 & 7.9 & 33.2 \\
\hline $\mathrm{HU}$ & 256 & 7.03 & 2.31 & 56.2 & 7.0 & 22.6 & 83.2 & 70.7 & 70.7 & 5.4 & 58.5 \\
\hline IE & 379 & 8.21 & 1.51 & 69.6 & 0.7 & 73.8 & 84.7 & 84.7 & 62.5 & 26.3 & 34.0 \\
\hline IS & 107 & 8.57 & 1.30 & 43.9 & 2.8 & 14.0 & 87.8 & 93.4 & 75.7 & 20.5 & 54.2 \\
\hline IT & 107 & 6.28 & 2.31 & 58.8 & 0.0 & 53.2 & 83.1 & 68.2 & 63.5 & 18.6 & 33.6 \\
\hline LU & 271 & 7.92 & 1.74 & 69.3 & 4.4 & 27.3 & 79.7 & 76.01 & 52.4 & 23.2 & 38.0 \\
\hline NL & 358 & 7.89 & 1.29 & 61.1 & 4.1 & 19.2 & 73.4 & 87.7 & 75.7 & 39.6 & 24.8 \\
\hline NO & 333 & 8.20 & 1.44 & 38.7 & 3.9 & 10.8 & 74.7 & 85.8 & 85.2 & 23.4 & 51.9 \\
\hline PL & 337 & 7.06 & 2.23 & 47.1 & 5.3 & 81.3 & 86.9 & 87.5 & 53.1 & 10.6 & 51.0 \\
\hline PT & 322 & 7.04 & 1.57 & 76.0 & 2.8 & 36.9 & 77.0 & 68.3 & 53.7 & 5.2 & 61.4 \\
\hline $\mathrm{SE}$ & 328 & 8.18 & 1.30 & 31.7 & 3.9 & 7.6 & 71.0 & 90.5 & 67.3 & 14.9 & 63.1 \\
\hline SI & 224 & 7.69 & 1.66 & 41.9 & 4.4 & 26.7 & 87.0 & 83.9 & 69.6 & 1.7 & 76.7 \\
\hline SK & 251 & 6.46 & 2.25 & 50.6 & 3.5 & 43.0 & 92.0 & 85.2 & 60.5 & 2.7 & 60.5 \\
\hline TR & 477 & 6.96 & 2.41 & 76.52 & 9.0 & 10.2 & 87.2 & 41.5 & 57.2 & 2.3 & 7.5 \\
\hline UA & 317 & 6.20 & 2.09 & 39.75 & 8.2 & 26.8 & 81.7 & 77.9 & 100.0 & 5.0 & 48.2 \\
\hline UK & 294 & 7.51 & 1.75 & 59.1 & 2.7 & 19.3 & 73.4 & 77. & 73.4 & 30.9 & 34.3 \\
\hline
\end{tabular}


Figure 1: \% of women between 20 and 50 engaged in more or less than $75 \%$ of household work

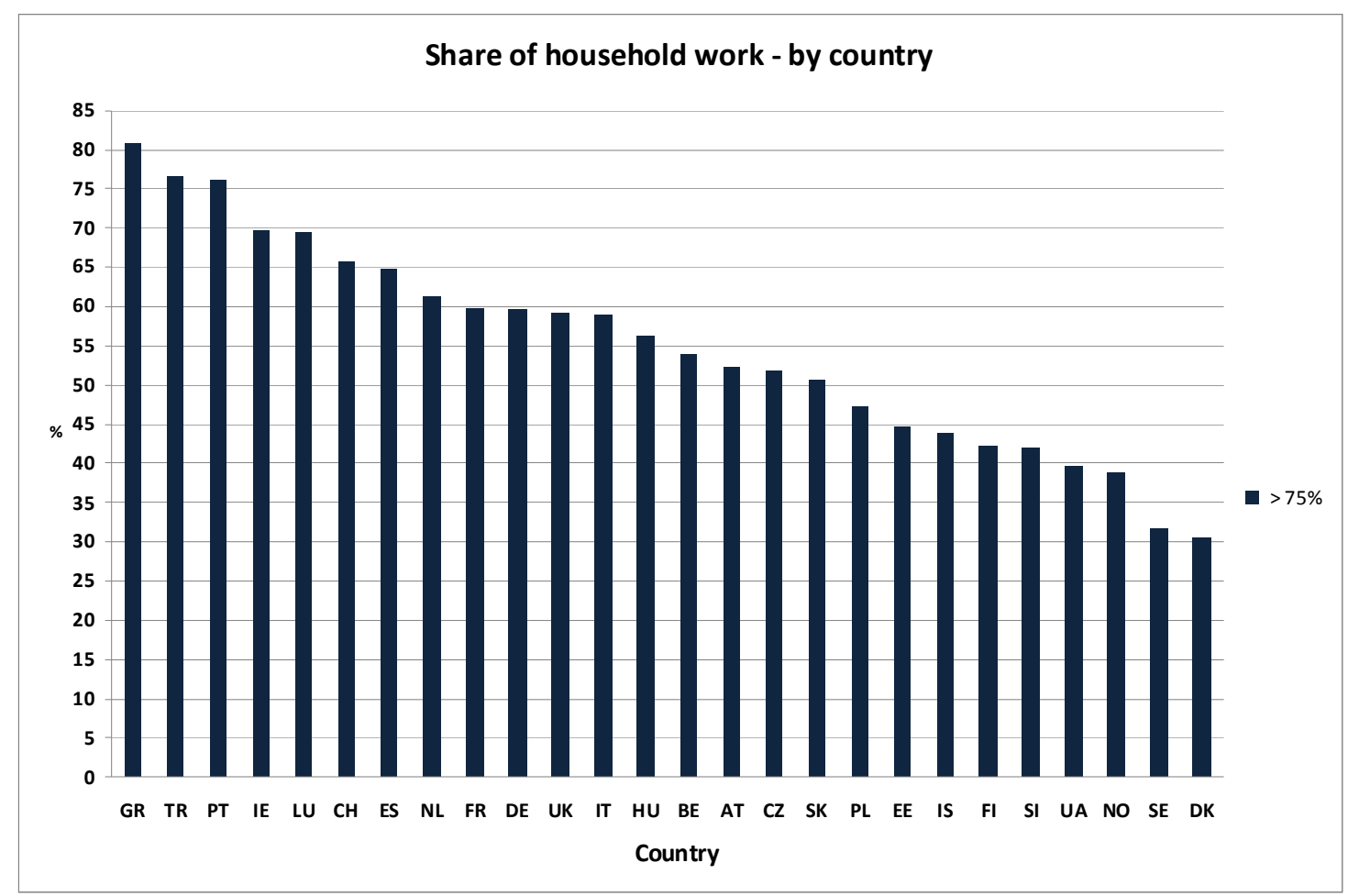

Source: own elaboration on 2004 ESS data.

Figure 2: Average happiness and share of housework, by country

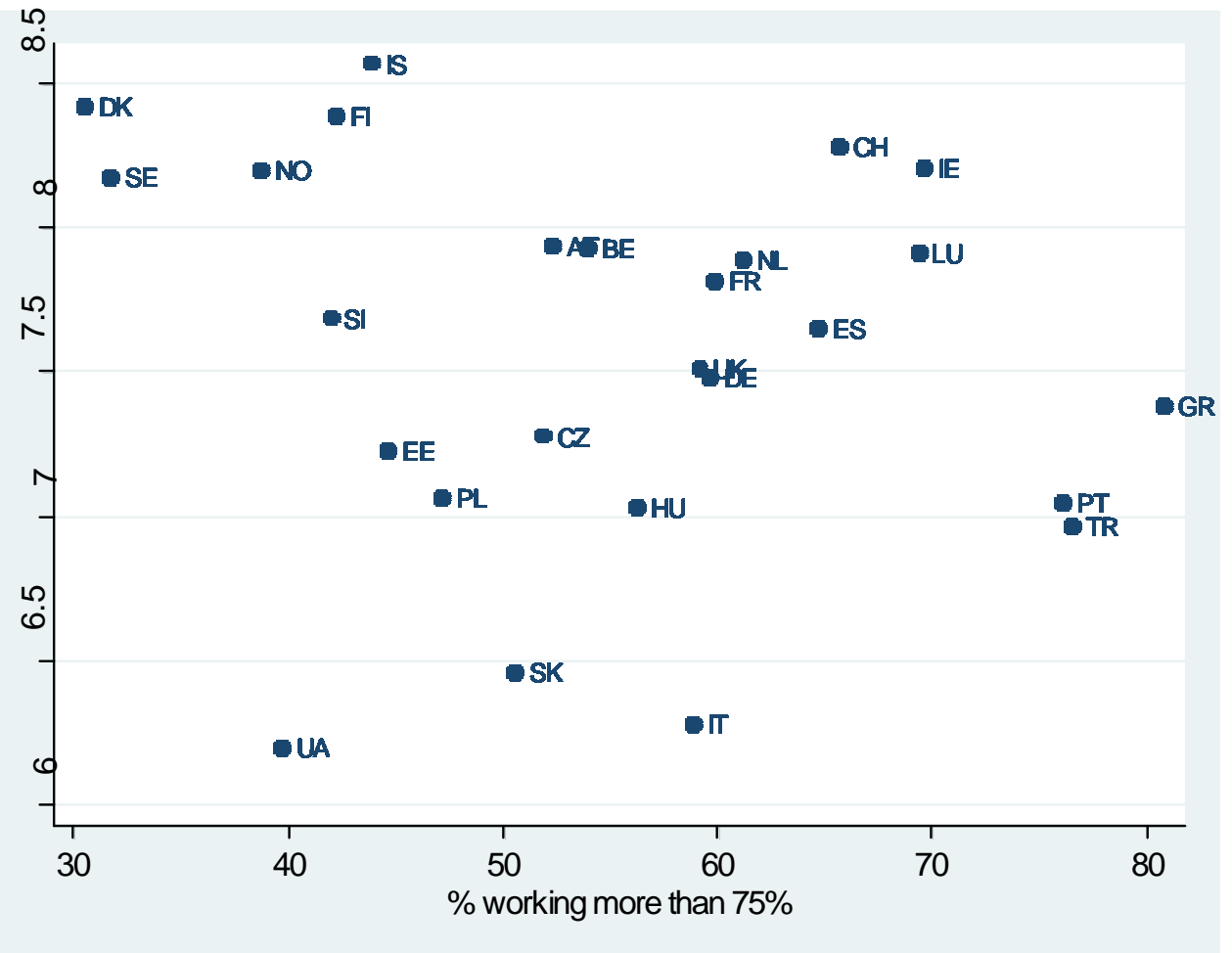

Source: own elaboration on 2004 ESS data. For country codes, see note 4. 
TABLE 2 Data on female labour force participation rate and global gender gap in European countries

\begin{tabular}{|c|c|c|}
\hline & $\begin{array}{l}\text { Labour force participation } \\
\quad \text { rate (2004), female }\end{array}$ & $\begin{array}{l}\text { Global Gender Gap } \\
\text { (2006) }\end{array}$ \\
\hline Country & $\%$ & Value \\
\hline Austria & 63.5 & 0.698 \\
\hline Belgium & 57.0 & 0.078 \\
\hline Czech Republic & 63.7 & 0.671 \\
\hline Denmark & 74.3 & 0.746 \\
\hline Estonia & 64.3 & 0.694 \\
\hline Finland & 72.8 & 0.795 \\
\hline France & 62.4 & 0.652 \\
\hline Germany & 66.5 & 0.752 \\
\hline Greece & 54.6 & 0.654 \\
\hline Hungary & 53.3 & 0.669 \\
\hline Iceland & 82.7 & 0.781 \\
\hline Ireland & 60.5 & 0.733 \\
\hline Italy & 49.5 & 0.645 \\
\hline Luxembourg & 54.4 & 0.667 \\
\hline Netherlands & 69.1 & 0.725 \\
\hline Norway & 77.1 & 0.799 \\
\hline Poland & 57.7 & 0.680 \\
\hline Portugal & 67.1 & 0.692 \\
\hline Slovakia & 62.4 & 0.675 \\
\hline Slovenia & 66.1 & 0.674 \\
\hline Spain & 55.9 & 0.731 \\
\hline Sweden & 75.1 & 0.813 \\
\hline Switzerland & 74.9 & 0.699 \\
\hline Turkey & 29.0 & 0.585 \\
\hline Ukraine & 63.3 & 0.679 \\
\hline United Kingdom & 69.2 & 0.736 \\
\hline Source & $\begin{array}{l}\text { UN Statistics Division: } \\
\text { http://data.un.org/ }\end{array}$ & $\begin{array}{c}\text { Global Gender Gap Report 2006: } \\
\text { http://www.weforum.org }\end{array}$ \\
\hline
\end{tabular}


TABLE 3 Multilevel analysis of housework effects on women subjective well-

\section{being}

\begin{tabular}{|c|c|c|c|c|c|}
\hline Women 20-50 & (1) Null & $(2)$ & (3) & (4) & (5) \\
\hline Share of household work $\geq 75 \%$ & & $\begin{array}{l}-0.089 * * * \\
(0.025)\end{array}$ & & $\begin{array}{l}-0.088 * * * \\
(0.025)\end{array}$ & $\begin{array}{l}-0.088 * * * \\
(0.025)\end{array}$ \\
\hline Country median share of household work & & & $\begin{array}{l}0.021 \\
(0.167)\end{array}$ & & \\
\hline Share higher than the country's median & & & $\begin{array}{l}-0.060 * * \\
(0.028)\end{array}$ & & \\
\hline Age & & $\begin{array}{l}-0.040 * * * \\
(0.015)\end{array}$ & $\begin{array}{l}-0.041 * * * \\
(0.015)\end{array}$ & $\begin{array}{l}-0.040 * * * \\
(0.015)\end{array}$ & $\begin{array}{l}-0.039 * * * \\
(0.015)\end{array}$ \\
\hline Age squared & & $\begin{array}{l}0.0003 * \\
(0.0002)\end{array}$ & $\begin{array}{l}0.0004 * \\
(0.0002)\end{array}$ & $\begin{array}{l}0.0004 * \\
(0.0002)\end{array}$ & $\begin{array}{l}0.0004 * \\
(0.0002)\end{array}$ \\
\hline Church attendance & & $\begin{array}{l}0.136 * * * \\
(0.030)\end{array}$ & $\begin{array}{l}0.135 * * * \\
(0.030)\end{array}$ & $\begin{array}{l}0.136 * * * \\
(0.030)\end{array}$ & $\begin{array}{l}0.136 * * * \\
(0.030)\end{array}$ \\
\hline Subjective general health & & $\begin{array}{l}0.693 * * * \\
(0.059)\end{array}$ & $\begin{array}{l}0.693 * * * \\
(0.059)\end{array}$ & $\begin{array}{l}0.693 * * * \\
(0.059)\end{array}$ & $\begin{array}{l}0.693 * * * \\
(0.059)\end{array}$ \\
\hline Number of children in the Household & & $\begin{array}{l}0.023 * * \\
(0.011)\end{array}$ & $\begin{array}{l}0.022 * * \\
(0.011)\end{array}$ & $\begin{array}{l}0.023 * * \\
(0.011)\end{array}$ & $\begin{array}{l}0.023 * * \\
(0.011)\end{array}$ \\
\hline Unpaid help & & $\begin{array}{l}0.171 * * * \\
(0.029)\end{array}$ & $\begin{array}{l}0.173 * * * \\
(0.029)\end{array}$ & $\begin{array}{l}0.169 * * * \\
(0.029)\end{array}$ & $\begin{array}{l}0.169 * * * \\
(0.029)\end{array}$ \\
\hline High income & & $\begin{array}{l}0.166 * * * \\
(0.026)\end{array}$ & $\begin{array}{l}0.168 * * * \\
(0.026)\end{array}$ & $\begin{array}{l}0.165 * * * \\
(0.026)\end{array}$ & $\begin{array}{l}0.165 * * * \\
(0.026)\end{array}$ \\
\hline Hours worked per week - b/w 10 and 30 & & $\begin{array}{l}0.039 \\
(0.037)\end{array}$ & $\begin{array}{l}0.048 \\
(0.037)\end{array}$ & $\begin{array}{l}0.038 \\
(0.037)\end{array}$ & $\begin{array}{l}0.038 \\
(0.037)\end{array}$ \\
\hline Hours worked per week - 31 or more & & $\begin{array}{l}-0.048^{*} \\
(0.029)\end{array}$ & $\begin{array}{l}-0.036 \\
(0.029)\end{array}$ & $\begin{array}{l}-0.050 * \\
(0.029)\end{array}$ & $\begin{array}{l}-0.050 * \\
(0.029)\end{array}$ \\
\hline Female Labour Force Participation Rate ${ }^{\circ}$ & & & & $\begin{array}{l}0.017 * * * \\
(0.006)\end{array}$ & \\
\hline Global Gender Gap ${ }^{\circ}$ & & & & & $\begin{array}{l}0.041 * * * \\
(0.011)\end{array}$ \\
\hline LR test (p-value) & $\begin{array}{l}0.000 \\
\text { Multilevel }\end{array}$ & $\begin{array}{l}0.000 \\
(1)-(2) \\
\end{array}$ & $\begin{array}{l}0.000 \\
(1)-(4) \\
\end{array}$ & $\begin{array}{l}0.0074 \\
(2)-(5) \\
\end{array}$ & $\begin{array}{l}0.0007 \\
(2)-(6) \\
\end{array}$ \\
\hline Number of observations & 8031 & 8031 & 8031 & 8031 & 8031 \\
\hline Variance across countries & $\begin{array}{l}0.125 * * * \\
(0.036)\end{array}$ & $\begin{array}{l}0.136 * * * \\
(0.031)\end{array}$ & $\begin{array}{l}0.128 * * * \\
(0.034)\end{array}$ & $\begin{array}{l}0.096 * * * \\
(0.028)\end{array}$ & $\begin{array}{l}0.080 * * * \\
(0.024)\end{array}$ \\
\hline Intra-class correlation coefficient & 0,111 & 0,120 & 0,113 & 0,088 & 0,074 \\
\hline
\end{tabular}

${ }^{\circ} 2004 ;{ }^{\circ} 2006$

Source: own elaboration on 2004 ESS data

Note: standard errors in parenthesis. P-values: $+p<=0.10: *+p<=0.05: * *+p<=0.01 * * *$. 


\section{TABLE 4 Multilevel analysis of housework effects on working women subjective well-being}

\begin{tabular}{|c|c|c|c|c|c|}
\hline & & & & & \\
\hline Only Working Women & (6) Null & (7) & $(8)$ & $(9)$ & $(10)$ \\
\hline Share of household work $\geq 75 \%$ & & $-0.100 * * *$ & & $-0.097 * * *$ & $-0.097 * * *$ \\
\hline & & $(0.030)$ & & $(0.030)$ & $(0.030)$ \\
\hline Country median share of household work & & & 0.038 & & \\
\hline & & & $(0.185)$ & & \\
\hline Share higher than the country's median & & & $-0.082 * *$ & & \\
\hline & & & $(0.033)$ & & \\
\hline Age & & $-0.052 * *$ & $-0.052 * *$ & $-0.051 * *$ & $-0.051 * *$ \\
\hline & & $(0.020)$ & $(0.020)$ & $(0.020)$ & $(0.020)$ \\
\hline Age squared & & $0.0005^{*}$ & $0.0005^{*}$ & $0.0005^{*}$ & $0.0005^{*}$ \\
\hline & & $(0.0003)$ & $(0.0003)$ & $(0.0003)$ & $(0.0003)$ \\
\hline Church attendance & & $0.101 * * *$ & $0.101 * * *$ & $0.102 * * *$ & $0.102 * * *$ \\
\hline & & $(0.039)$ & $(0.040)$ & $(0.039)$ & $(0.039)$ \\
\hline Subjective general health & & $0.726 * * *$ & $0.736 * * *$ & $0.725 * * *$ & $0.725 * * *$ \\
\hline & & $(0.105)$ & $(0.104)$ & $(0.105)$ & $(0.105)$ \\
\hline Number of children in the Household & & 0.020 & 0.019 & 0.021 & 0.021 \\
\hline & & $(0.015)$ & $(0.015)$ & $(0.015)$ & $(0.015)$ \\
\hline Unpaid help & & $0.161 * * *$ & $0.164 * * *$ & $0.157 * * *$ & $0.157 * * *$ \\
\hline & & $(0.039)$ & $(0.039)$ & $(0.039)$ & $(0.039)$ \\
\hline High income & & $0.106 * * *$ & $0.109 * * *$ & $0.104 * * *$ & $0.104 * * *$ \\
\hline & & $(0.036)$ & $(0.036)$ & $(0.036)$ & $(0.036)$ \\
\hline Hours worked per week - 31 or more & & $-0.100 * * *$ & $-0.094 * *$ & $-0.098 * * *$ & $-0.097 * * *$ \\
\hline & & $(0.037)$ & $(0.037)$ & $(0.037)$ & $(0.037)$ \\
\hline Female Labour Force Participation Rate ${ }^{\circ}$ & & & & $0.023 * * *$ & \\
\hline & & & & $(0.006)$ & \\
\hline Global Gender Gap ${ }^{\circ}$ & & & & & $0.048 * * *$ \\
\hline & & & & & $(0.012)$ \\
\hline LR test (p-value) & 0.000 & 0.000 & 0.000 & 0.001 & 0.0002 \\
\hline & Multilevel & $(7)-(8)$ & $(7)-(10)$ & $(8)-(11)$ & $(8)-(12)$ \\
\hline Number of observations & 4968 & 4968 & 4968 & 4968 & 4968 \\
\hline Variance across countries & $0.157 * * *$ & $0.150 * * *$ & $0.152 * * *$ & $0.097 * * *$ & $0.087 * * *$ \\
\hline & $(0.046)$ & $(0.044)$ & $(0.045)$ & $(0.029)$ & $(0.026)$ \\
\hline Intra-class correlation coefficient & 0,136 & 0,130 & 0,132 & 0,088 & 0,080 \\
\hline
\end{tabular}

${ }^{\circ} 2004 ;{ }^{\circ} 2006$

Source: own elaboration on 2004 ESS data

Note: standard errors in parenthesis. P-values: $+\mathrm{p}<=0.10: *+\mathrm{p}<=0.05: * *+\mathrm{p}<=0.01 * * *$.

\footnotetext{
${ }^{\mathrm{i}}$ In what follows, subjective well-being, life satisfaction, and happiness, though not identical, are treated as reasonably interchangeable terms.

${ }^{\text {ii }}$ However, computing average happiness in each country using the original sample reveals that also among men and women living alone the distribution of happiness is right skewed (the average is 7.44 with a standard deviation of 1.9)

iii The number of household members may bias results about financial situation; hence we have to be careful when trying to interpret these figures. In Ukraine, surprisingly, all women between 20
} 
and 50, co-residing with a partner, has a "high" household income. Furthermore, they seem to be quite involved in the labour market outside the household.

${ }^{\text {iv }}$ Its inclusion in the different specifications has no impact on other variables coefficient. 